\title{
The relationship of Vascular endothelial growth factor gene polymorphisms and clinical outcome in advanced gastric cancer patients treated with FOLFOX: VEGF polymorphism in gastric cancer
}

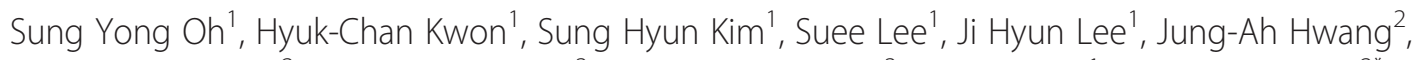 \\ Seung Hyun Hong ${ }^{2}$, Christian A Graves ${ }^{3}$, Kevin Camphausen ${ }^{3}$, Hyo-Jin Kim ${ }^{1}$ and Yeon-Su Lee ${ }^{2^{*}}$
}

\begin{abstract}
Background: The aim of this study is to evaluate the associations between vascular endothelial growth factor (VEGF) Single-nucleotide polymorphisms (SNPs) and clinical outcome in advanced gastric cancer patients treated with oxaliplatin, 5-fluorouracil, and leucovorin (FOLFOX).

Methods: Genomic DNA was isolated from whole blood, and six VEGF (-2578C/A, -2489C/T, -1498 T/C, -634 G/C, $+936 \mathrm{C} / \mathrm{T}$, and $+1612 \mathrm{G} / \mathrm{A}$ ) gene polymorphisms were analyzed by PCR. Levels of serum VEGF were measured using enzyme-linked immunoassays.

Results: Patients with G/G genotype for VEGF $-634 \mathrm{G} / \mathrm{C}$ gene polymorphism showed a lower response rate (22.2\%) than those with $\mathrm{G} / \mathrm{C}$ or $\mathrm{C} / \mathrm{C}$ genotype $(32.3 \%, 51.1 \% ; P=0.034)$. Patients with the VEGF $-634 \mathrm{G} / \mathrm{C}$ polymorphism $\mathrm{G} / \mathrm{C}+\mathrm{C} / \mathrm{C}$ genotype had a longer progression free survival (PFS) of 4.9 months, compared with the PFS of 3.5 months for those with the $\mathrm{G} / \mathrm{G}(P=0.043$, log-rank test). By multivariate analysis, this $\mathrm{G} / \mathrm{G}$ genotype of VEGF $-634 \mathrm{G} / \mathrm{C}$ polymorphism was identified as an independent prognostic factor (Hazard ratio 1.497, $P=0.017$ ).
\end{abstract}

Conclusion: Our data suggest that $\mathrm{G} / \mathrm{G}$ genotype of VEGF $-634 \mathrm{G} / \mathrm{C}$ polymorphism is related to the higher serum levels of VEGF, and poor clinical outcome in advanced gastric cancer patients.

Keywords: VEGF, Polymorphism, Gastric cancer

\section{Background}

Gastric cancer remains a significant health problem despite of declining incidence in the West. It is the 4th most common cancer worldwide, accounting for $8.6 \%$ of all new cancer diagnoses in 2002 [1]. Although the incidence of stomach cancer among Korean has decreased over the past two decades, gastric cancer is the most common carcinoma in men, and the third most common type of cancer in women as a leading cause of cancer death in Korea [2].

In case of the patients who were most newly diagnosed with gastric cancer or gastric cancer with distant metastasis, the mean 5-year survival rate is recognized to be poor

\footnotetext{
* Correspondence: yslee2@ncc.re.kr

${ }^{2}$ Cancer Genomics Branch, Research Institute, National Cancer Center, Goyang, Gyeonggi-do 410-769, Korea

Full list of author information is available at the end of the article
}

at less than $10 \%$ [3]. Up to date, no randomized study on combination chemotherapy has reported a median survival time exceeding 12 months [4]. 5-fluorouracil (5-FU) has been used as a main chemotherapeutic agent for the treatment of gastric cancer, and combination chemotherapy with 5-FU has shown improved clinical outcomes. Even though 5-FU with cisplatin is an effective agent, it has been considered to have a high level of toxicity [4]. Oxaliplatin, another platinum based agent, has a more favorable tolerability profile than cisplatin. The Folinic acid/5-FU/Oxaliplatin combination (FOLFOX) has proven to be an effective first- or second-line treatment agent for advanced gastric cancer $[5,6]$. However, some patients are predisposed to refractory diseases while others develop resistance after the initial response. Patients may also have a different severity of drug-related adverse events.

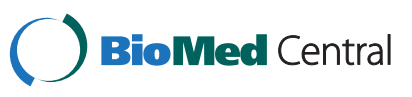


Increasing demand for improved techniques for the prediction of treatment response and survival may facilitate customized chemotherapy and risk-related therapy, resulting in significantly enhanced survival rates.

Vascular endothelial growth factor (VEGF) is a well known pro-angiogenic growth factor, and its stimulation under hypoxic conditions plays a critical role in promoting the survival of malignant cells in local tumor growth and invasion, and in the development of metastases [7]. Several important roles of VEGF in the progression of human gastric cancer have been reported. The expression of VEGF-A is correlated with tumor vascularity [8], and the frequency of hepatic metastases increased significantly among patients with VEGF positive tumors [9]. The expression of VEGF-A is also correlated with a poor outcome, and is an independent prognostic factor in gastric cancer patients $[8,9]$.

The VEGF gene is located on chromosome 6p21.3, and contains eight exons being separated by seven introns. Several single nucleotide polymorphisms (SNPs) have been described in the VEGF gene some of which have been shown to affect the expression of the gene [10]. Among these SNPs there are five SNPs $(-2578 \mathrm{C} / \mathrm{A},-1154 \mathrm{G} / \mathrm{A},-460 \mathrm{~T} / \mathrm{C}$ in the VEGF promoter region, $+405 \mathrm{G} / \mathrm{C}$ in the $5^{\prime}$-untranslated region and $+936 \mathrm{C} / \mathrm{T}$ in the $3^{\prime}$-untranslated region) that are common and are related to VEGF protein synthesis [11]. Very limited amount of published data on VEGF polymorphisms in association with gastric cancer prognosis is available, and the results are diverging $[12,13]$. These studies show an increased level of association of gastric cancer and/or poor clinical outcomes in the subgroup with genotypes, which would predict a higher level of VEGF expression.

VEGF not only promotes neovascularization and migration but also increases vascular permeability and leakage [14]. This results in an elevated interstitial fluid pressure that prevents effective transport of therapeutic drugs into tumors and thereby, reduces the efficacy of anti-cancer treatment. SNPs in VEGF may alter VEGF protein concentrations, and may relate to inter-individual variation in the risk and progression of selected tumors, and their resistance to treatments. There were few reports that showed the predictive value of VEGF polymorphism to FOLFOX or capecitabine and oxalipatin (XELOX) chemotherapy in colorectal cancer $[15,16]$. However, no study that has investigated the SNPs of the VEGF gene, and their relationship to the clinical outcomes of gastric cancer patients treated with FOLFOX has yet been published.

The purpose of the present study is to investigate whether VEGF SNPs are associated with clinical outcomes of patients with advanced gastric cancer treated with first-line FOLFOX palliative chemotherapy or not.

\section{Methods}

\section{Study population}

All patients in this study had histologically confirmed adenocarcinoma of the stomach. These patients were treated by FOLFOX chemotherapy. All patients who were in their ages of 18 through 79 had a performance status with a score less than or equal to two according to the Eastern Cooperative Oncology Group scale, and adequate bone marrow as well as renal function Previous adjuvant chemotherapy must be completed at least 6 months before inclusion. Exclusion criteria included the presence of central nervous system metastases, serious or uncontrolled concurrent medical illness, and a history of other malignancies. Written informed consent was obtained from each patient before study entry. The use of all patient materials was approved by the institutional review board of Dong-A University Hospital.

\section{Patient characteristics}

From March 2007 to August 2010, a total of 190 patients enrolled into this study. Demographic details on the patients included in the study are shown in Table 1.

\section{Table 1 Patients' characteristics}

\begin{tabular}{|c|c|c|c|}
\hline Variable & Subgroup & No. of patients & $\%$ \\
\hline \multirow[t]{2}{*}{ Sex } & Male & 125 & 65.8 \\
\hline & Female & 65 & 34.2 \\
\hline \multirow[t]{2}{*}{ Age } & Median & 55 years & \\
\hline & Range & (24-79 years) & \\
\hline \multirow[t]{2}{*}{ ECOG performance status } & 0,1 & 186 & 97.9 \\
\hline & 2 & 4 & 2.1 \\
\hline \multirow[t]{4}{*}{ Lauren } & Intestinal & 26 & 13.7 \\
\hline & Diffuse & 41 & 21.6 \\
\hline & Mixed & 18 & 9.5 \\
\hline & Unknown & 105 & 55.3 \\
\hline \multirow[t]{4}{*}{ Initial stage } & 1 & 8 & 4.2 \\
\hline & 2 & 28 & 14.7 \\
\hline & 3 & 41 & 21.6 \\
\hline & 4 & 113 & 59.5 \\
\hline \multirow[t]{2}{*}{ Operation } & + & 127 & 66.8 \\
\hline & - & 63 & 33.2 \\
\hline \multirow[t]{2}{*}{ Adjuvant therapy } & + & 79 & 41.6 \\
\hline & - & 111 & 58.4 \\
\hline \multirow[t]{3}{*}{ No. of metastasis } & 1 & 106 & 55.8 \\
\hline & 2 & 54 & 28.4 \\
\hline & $>3$ & 30 & 15.8 \\
\hline \multirow[t]{3}{*}{ CEA } & $<5 \mathrm{ng} / \mathrm{ml}$ & 119 & 62.6 \\
\hline & $\geq 5 \mathrm{ng} / \mathrm{ml}$ & 54 & 28.4 \\
\hline & Unchecked & 17 & 8.9 \\
\hline
\end{tabular}

ECOG: eastern cooperative oncology group, CEA: carcinoembryonic antigen. 
The patients consisted of 125 men and 65 women, and their median age was 55 (ranging 24-79). Ninty-seven patients underwent curative operation (stage I, 8; stage II, 28 ; stage III, 41; stage IV(M0), 20), and a palliative resection was done in 30-stage IV patients. Seventy-nine patients (41.6\%) received 5-FU-based adjuvant chemotherapy. Almost all patients had a good performance status. No significant association was detected between the genotypes of the SNPs and patient characteristics (data not shown). Genotyping for the six VEGF polymorphisms were obtained from all 143 patients. The frequencies of each genotype are shown in Table 2.

\section{Treatment protocols and dose modification}

On day 1 , oxaliplatin $\left(85 \mathrm{mg} / \mathrm{m}^{2}\right)$ was administered by intravenous (i.v.) infusion in $500 \mathrm{ml}$ of normal saline or dextrose over $2 \mathrm{~h}$. On day 1 and 2 , leucovorin $\left(20 \mathrm{mg} / \mathrm{m}^{2}\right)$ was administered as an i.v. bolus, immediately followed by 5 -FU $\left(400 \mathrm{mg} / \mathrm{m}^{2}\right)$ given as a 10 -min i.v. bolus, followed by 5 -FU $\left(600 \mathrm{mg} / \mathrm{m}^{2}\right)$ as a continuous 22 -h infusion with a light shield. Dose modifications of oxaliplatin or 5 -FU were made for hematologic, gastrointestinal, or neurologic toxic effects on the basis of the most severe grade of toxicity that had occurred during the previous cycle. Treatment could be delayed for up to 2 weeks if symptomatic toxicity persisted, or if the absolute number of neutrophils

Table 2 Distribution of genotypes and serum levels of vascular endothelial growth factor

\begin{tabular}{|c|c|c|c|c|c|}
\hline Genotype & Polymorphism & $\begin{array}{c}\text { No. of } \\
\text { patients }\end{array}$ & $\%$ & $\begin{array}{c}\text { Mean } \pm \text { SD } \\
(p g / m l)\end{array}$ & $P^{*}$ \\
\hline \multirow[t]{3}{*}{$-2578 \mathrm{C} / \mathrm{A}$} & CC & 116 & 61.1 & $453.2 \pm 278.8$ & 0.606 \\
\hline & CA & 63 & 33.2 & $520.0 \pm 392.3$ & \\
\hline & $\mathrm{AA}$ & 11 & 5.8 & $523.9 \pm 391.7$ & \\
\hline \multirow[t]{3}{*}{$-2489 C / \top$} & $\mathrm{CC}$ & 116 & 61.1 & $453.2 \pm 278.8$ & 0.117 \\
\hline & $\mathrm{CT}$ & 60 & 31.6 & $478.4 \pm 350.0$ & \\
\hline & $\pi$ & 14 & 7.4 & $724.0 \pm 517.7$ & \\
\hline \multirow[t]{3}{*}{-1498 T/C } & $\pi$ & 116 & 61.1 & $453.2 \pm 278.8$ & 0.563 \\
\hline & $\mathrm{TC}$ & 61 & 32.1 & $512.2 \pm 400.7$ & \\
\hline & CC & 13 & 6.8 & $568.2 \pm 324.9$ & \\
\hline \multirow[t]{3}{*}{$-634 \mathrm{G} / \mathrm{C}$} & GG & 54 & 28.4 & $889.7 \pm 453.7$ & 0.004 \\
\hline & $\mathrm{GC}$ & 93 & 48.9 & $471.4 \pm 222.6$ & \\
\hline & $\mathrm{CC}$ & 43 & 22.6 & $410.7 \pm 222.6$ & \\
\hline \multirow[t]{3}{*}{$+936 \mathrm{C} / \mathrm{T}$} & $\mathrm{CC}$ & 135 & 71.1 & $440.0 \pm 292.0$ & 0.722 \\
\hline & $\mathrm{CT}$ & 45 & 23.7 & $495.5 \pm 329.3$ & \\
\hline & $\pi$ & 10 & 5.3 & $502.6 \pm 371.1$ & \\
\hline \multirow[t]{3}{*}{$+1612 \mathrm{G} / \mathrm{A}$} & GG & 139 & 73.2 & $472.4 \pm 339.2$ & 0.371 \\
\hline & GA & 47 & 24.7 & $538.3 \pm 295.9$ & \\
\hline & AA & 4 & 2.1 & $267.0 \pm 159.3$ & \\
\hline
\end{tabular}

*by Mann-Whitney.

SD: standard deviation. was $<1,500 / \mu \mathrm{l}$ or platelets count was $<100,000 / \mu \mathrm{l}$. The 5 -FU dose was reduced by $25 \%$ for subsequent courses after National Cancer Institute Common Toxicity Criteria (NCI-CTC) grade 3 diarrhea, stomatitis, or dermatitis had occurred. The dose of oxaliplatin was reduced by $25 \%$ in subsequent cycles if there were persistent paresthesias between cycles or paresthesias with functional impairment lasting $>7$ days. Treatment was continued until there were signs of disease progression, unacceptable toxic effects developed, or the patient refused further treatment.

\section{Follow-up evaluation and assessment of response}

Before each treatment course, a physical examination, routine hematology, biochemistry, and chest X-ray were carried out. Computed tomography scans to define the extent of the disease, and the responses were carried out after four cycles of chemotherapy, or sooner if there was evidence of any clinical deterioration. Patients were assessed before starting each 2-week cycle using the NCI-CTC, except in the case of neurotoxicity. For the neurotoxicity, an oxaliplatin-specific scale was used: grade 1, paresthesias or dysesthesias of short duration, but resolving before the next dosing; grade 2, paresthesias persisting between doses (2 weeks); and grade 3, paresthesias interfering with function.

Responses were evaluated using RECIST criteria. Complete response (CR) was defined as the disappearance of all evidences of disease and the normalization of tumor markers for at least 2 weeks. Partial response (PR) was defined as $\geq 30 \%$ reduction in uni-dimensional tumor measurements, without the appearance of any new lesions or the progression of any existing lesion. Progressive disease (PD) was defined as any of the following: $20 \%$ increase in the sum of the products of all measurable lesions, appearance of any new lesion, or reappearance of any lesion that had previously disappeared. Stable disease (SD) was defined as a tumor response not fulfilling the criteria for $\mathrm{CR}, \mathrm{PR}$, or PD.

\section{Measurements of serum levels of VEGF}

Blood sample was drawn from each participant through venipuncture before chemotherapy and after three cycles of treatment. The blood samples were centrifuged for $10 \mathrm{~min}$ at $3,000 \mathrm{r} / \mathrm{min}$ at $-4^{\circ} \mathrm{C}$. The serum was subsequently removed and stored at $-80^{\circ} \mathrm{C}$ until biochemical analysis. Serum VEGF enzyme-linked immunosorbent assay (ELISA) was completed as per manufacturer protocols (R\&D Systems, Minneapolis MN). Briefly, serum samples were thawed on wet ice three hours prior to assay. Serum samples were pre-treated with an acidic solution to promote dissociation of VEGF from abundant VEGF binding proteins and stabilized in buffer and preservatives. Samples were plated in 96 well format in duplicate after each of conjugated VEGF-1/HRP polyclonal 
secondary antibody was added. Substrate solution $\left(\mathrm{H}_{2} \mathrm{O}_{2} /\right.$ tetramethylbenzidine) was then administered for thirty minutes after the reaction was quenched with sulfuric acid. Plates were read at an absorbance of $450 \mathrm{~nm}$ on a Victor 3 plate reader (Perkin Elmer, Boston MA). Extrapolated absorbance was analyzed using Masterplex Readerfit ELISA software (Hitachi, Waltham MA) and concentration was determined following a 4 Parameter Logistic curve fit as per manufacturer's recommendation. Measurements were made by the single investigator blinded to the patients' clinicopathological data.

\section{DNA extraction and sample preparation}

DNA was extracted from the 75 ul buffy coat using the MagAttract DNA Blood Midi M48 Kit (Qiagen, Inc), using a Qiagen BioRobot M48 workstation, according to the manufacturer's protocols automatically. The purity and concentration of isolated DNA were determined by Nanodrop ${ }^{\circledR}$ ND-1000 spectrophotometer (Nanodrop technologies, DE, USA). Since we needed more detailed quantity of each sample for genotyping reaction, we measured the quantity of DNA using the Quant-iT ${ }^{\mathrm{TM}}$ PicoGreen ${ }^{\circledR}$ dsDNA Assay Kit (Molecular Probes, Inc., USA). We made dry plates for genotyping reaction with $10 \mathrm{ng}$ in each well of 384 plates.

\section{Candidate polymorphisms and primer design}

SNPs were selected from the previous study (11). The six SNPs analyzed were VEGF -2578 C/A SNP (rs699947), VEGF -1498 C/A SNP (rs833061), VEGF -634 G/C SNP (rs2010963), VEGF +936 C/T SNP (rs3025039), and VEGF +1612 G/A SNP (rs10434). The multiplexed assay group was designed to test up to 18 SNPs in the same reaction group using MassARRAY Assay Designer v3.0 (Sequenom, CA).

\section{Genotyping}

Genotyping was carried out using the iPLEX Gold ${ }^{\mathrm{TM}}$ assay on the MassARRAY ${ }^{\circledR}$ Platform (Sequenom, CA). PCR reactions were performed in a total volume of $5 \mathrm{ul}$ with $10 \mathrm{ng}$ of genomic DNA, $1.625 \mathrm{mM} \mathrm{MgCl} 2,0.1$ unit of HotStarTaq polymerase (Qiagen, Valencia, CA), $0.5 \mathrm{mM}$ dNTP (Invitrogen, Inc.), and $100 \mathrm{nM}$ primers. The PCR reactions started at $94^{\circ} \mathrm{C}$ for $15 \mathrm{~min}$, followed by 45 cycles at $94^{\circ} \mathrm{C}$ for $20 \mathrm{~s}, 50^{\circ} \mathrm{C}$ for $30 \mathrm{~s}$, and $72^{\circ} \mathrm{C}$ for $1 \mathrm{~min}$, with the final extension at $72^{\circ} \mathrm{C}$ for $3 \mathrm{~min}$. Amplified PCR products were treated by SAP mixture in a total 7ul with Shirimp Alkaline Phosphatase enzyme \& buffer. SAP reaction started at $37^{\circ} \mathrm{C}$ for $40 \mathrm{~min}$ and $85^{\circ} \mathrm{C}$ for $5 \mathrm{~min}$. The regions containing target SNP were amplified by PCR and treated by SAP followed by single base extension reaction, resulting in an allele-specific difference in mass between extension products. The extension reactions were performed in a total volume of $9 \mathrm{ul}$ with
$50 \mathrm{uM}$ dNTP/dideoxynucleotide phosphate (ddNTP) each, 0.063 unit/ul Thermo Sequenase (both from SEQUENOM, Inc.), and $625 \mathrm{nM}$ to $1.25 \mathrm{uM}$ extension primers. Under the cycling conditions, two cycling loops, one of five cycles that sits inside a loop of 40 cycles were used. The sample was denatured at $94^{\circ} \mathrm{C}$. Strands are annealed at $52^{\circ} \mathrm{C}$ for $5 \mathrm{~s}$ and extended at $80^{\circ} \mathrm{C}$ for $5 \mathrm{~s}$. The annealing and extension cycle was repeated four more times for a total of five cycles and then, looped back to the $94^{\circ} \mathrm{C}$ denaturing step for $5 \mathrm{~s}$. After then, the 5-cycle annealing and extension loop was conducted again. The five annealing and extension steps with the single denaturing step were repeated additional 39 times for a total of 40 . The 40 cycles of the 5-cycle annealing and extension steps equate to a total of 200 cycles $(5 \times 40)$. A final extension was done at $72^{\circ} \mathrm{C}$ for three minutes and then, the sample wascooled down up to $4^{\circ} \mathrm{C}$. After cleaning up the extension reaction products with SpectroCLEAN, the products were transferred to SpectroCHIP using SpectroPOINT and then, scanned through SpectroREADER (MALDI-TOF). Resulting genotype data were collected by Typer v4.0 (Sequenom, CA).

\section{Statistical analysis}

Serum levels of VEGF were expressed as the means \pm standard deviation. Associations between VEGF SNPs and levels of serum VEGF were assessed by MannWhitney test. The association between VEGF SNPs and response to chemotherapy was assessed by $\chi^{2}$ statistics.

The primary end point of the study was to investigate the association between genotypes and progression-free survival (PFS). The PFS and overall survival (OS) were calculated from the date therapy started from the date of disease progression and death, respectively. Patients who were alive at the last follow-up were screened at that time. Patients who were excluded from this study or who died before progression were screened at the time that they were excluded from this study. The association of each marker with survival was analyzed using Kaplan-Meier plots, the log-rank test, and its associated 95\% confidence interval (CI) was calculated. Hazard ratios (HRs) for survival, together with their 95\% CI, were calculated using Cox proportional hazards regression for age, gender, histological subgroup, performance status, disease stage, and polymorphism subtype.

All tests were two-sided, and $P<0.05$ was considered statistically significant. Analyses were done using SPSS version 14.0 (SPSS Inc, Chicago, IL).

\section{Results}

\section{VEGF genotype and chemotherapy response}

We analyzed the association of pretreatment serum levels of VEGF with VEGF SNPs. Distribution of VEGF genotypes and its serum levels of VEGF are shown in Table 2. 
Serum levels of VEGF was significantly higher in carriers of the $-634 \mathrm{G} / \mathrm{G}$ genotype compared to $\mathrm{G} / \mathrm{C}$ or $\mathrm{C} / \mathrm{C}$ $(889.7 \pm 453.7$ vs. $471.4 \pm 328.1$ vs. $410.7 \pm 222.6 \mathrm{pg} / \mathrm{ml}$, respectively, $P=0.004$ ). None of the other tested SNPs was associated with serum VEGF level.

The overall chemotherapy response rate for treatment was $34.2 \%$ (95\% CI: 20.0-40.5\%). Six patients achieved complete responses (3.2\%), 59 patients achieved partial responses (34.2\%), 76 patients showed a stable condition $(40.0 \%)$ and 49 showed a progressive status (25.8\%). Lauren's classification $(P=0.029)$ and number of metastasis were related to the response to chemotherapy $(P=0.034)$. Other parameters such as gender, age, previous operation, initial stage, adjuvant chemotherapy, and carcinoembryonic antigen (CEA) level were not significantly correlated with the clinical response to FOLFOX chemotherapy. VEGF SNPs and its association with responses are summarized in Table 3. The VEGF-A -634 G/G genotypes were related to inferior response rates compared with $\mathrm{G} / \mathrm{C}$ or $\mathrm{C} / \mathrm{C}$ genotypes $(22.2 \%, 32.3 \%, 51.1 \%$, respectively, $P=0.034)$. None of the other analyzed SNPs predicted a response rate.

\section{Association of VEGF genotype and survival}

The median duration of follow-up was 14.6 months (ranging 1.0-48.3 months). The PFS was 4.5 months (95\%

Table 3 Response according to genotyping of vascular endothelial growth factor

\begin{tabular}{llcll}
\hline Genotype & Polymorphism & ORR & $\%$ & $P^{*}$ \\
\hline$-2578 C / A$ & CC & $41 / 116$ & 35.3 & 0.798 \\
& CA & $20 / 63$ & 31.7 & \\
$-2489 C / T$ & AA & $3 / 11$ & 27.3 & \\
& CC & $41 / 116$ & 35.3 & 0.812 \\
& CT & $19 / 160$ & 31.7 & \\
$-1498 \mathrm{~T} / \mathrm{C}$ & T & $4 / 14$ & 28.6 & \\
& TC & $41 / 116$ & 30.8 & 0.832 \\
& CC & $19 / 61$ & 31.1 & \\
$-634 \mathrm{G} / \mathrm{C}$ & GG & $4 / 13$ & 35.3 & \\
& GC & $12 / 54$ & 22.2 & 0.034 \\
& CC & $30 / 93$ & 32.3 & \\
$+936 \mathrm{C} / \mathrm{T}$ & CC & $22 / 43$ & 51.1 & \\
& CT & $46 / 135$ & 34.1 & 0.852 \\
& TT & $14 / 45$ & 31.1 & \\
$+1612 \mathrm{G} / \mathrm{A}$ & GG & $4 / 10$ & 40.0 & \\
& GA & $50 / 139$ & 36.0 & 0.333 \\
& AA & $12 / 47$ & 25.5 & \\
\hline
\end{tabular}

*by Fisher's exact and chi-square test. ORR: overall response rate.
CI 3.8-5.1 months), and the median OS was 12.9 months (95\% CI 10.6-15.2 months). Among clinical parameters evaluated, gender, previous operation, Lauren's classification, adjuvant chemotherapy, CEA were not correlated with either PFS or OS. Patient's age was related to both PFS $(P=0.035)$ and OS $(P=0.011)$. Younger patients (less than 60 years of age) had better clinical outcomes. Table 4 shows the association of VEGF SNPs with PFS and OS in the 190 patients analyzed. Patients with the VEGF -634 G/C polymorphism $\mathrm{G} / \mathrm{C}+\mathrm{C} / \mathrm{C}$ genotype had a longer PFS of 4.9 months, compared with the PFS of 3.5 months for those with the $\mathrm{G} / \mathrm{G}(P=0.043$, Figure 1$)$. No significant influence on OS was observed by the VEGF -634 G/C. However, other VEGF SNPs were not related to PFS, or OS.

Factors that had statistical significance in the univariate models were included in multivariate model. In multivariate analysis, age (hazard ratio (HR): 1.521 , 95\% CI: $1.105-2.093, \mathrm{P}=0.010$ ), and number of metastasis (HR: $1.375,95 \% \mathrm{CI}: 1.129-1.674, \mathrm{P}=0.002$ ) remained as independent prognostic factors for PFS. The G/G genotype of $-634 \mathrm{G} / \mathrm{C}$ polymorphism was also identified as an independent prognostic factor for PFS (HR: 1.497, 95\% CI: 1.074-2.088, P = 0.017) (Table 5). No other VEGF SNPs were significant independent prognostic factors impacted on PFS.

Table 4 Univariate analysis according to the genotyping of vascular endothelial growth factor

\begin{tabular}{llccccc}
\hline Genotype & Polymorphism & $\begin{array}{c}\text { No. of } \\
\text { patients }\end{array}$ & $\begin{array}{c}\text { PFS } \\
\text { (Mo) }\end{array}$ & $P^{*}$ & $\begin{array}{c}\text { OS } \\
\text { (Mo) }\end{array}$ & $P^{*}$ \\
\hline$-2578 C / A$ & CC & 116 & 4.9 & 0.676 & 12.8 & 0.423 \\
& CA & 63 & 3.9 & & 14.4 & \\
& AA & 11 & 3.0 & & 11.5 & \\
-2489 C/T & CC & 116 & 4.9 & 0.249 & 12.8 & 0.462 \\
& CT & 60 & 4.0 & & 14.4 & \\
& TT & 14 & 2.9 & & 11.5 & \\
-1498 T/C & TT & 116 & 4.9 & 0.647 & 12.8 & 0.440 \\
& TC & 61 & 3.9 & & 13.7 & \\
& CC & 13 & 3.0 & & 11.8 & \\
-634 G/C & GG & 54 & 3.5 & 0.043 & 13.1 & 0.407 \\
& GC & 93 & 4.8 & & 14.4 & \\
& CC & 43 & 4.9 & & 11.5 & \\
+936C/T & CC & 135 & 4.5 & 0.925 & 13.1 & 0.711 \\
& CT & 45 & 4.7 & & 11.9 & \\
& TT & 10 & 3.9 & & 11.9 & \\
+1612 G/A & GG & 139 & 4.4 & 0.448 & 12.8 & 0.644 \\
& GA & 47 & 5.0 & & 14.4 & \\
& AA & 4 & 2.1 & & 10.6 & \\
\hline
\end{tabular}

*by log-rank test.

PFS: progression free survival, Mo: months, OS: overall survival. 


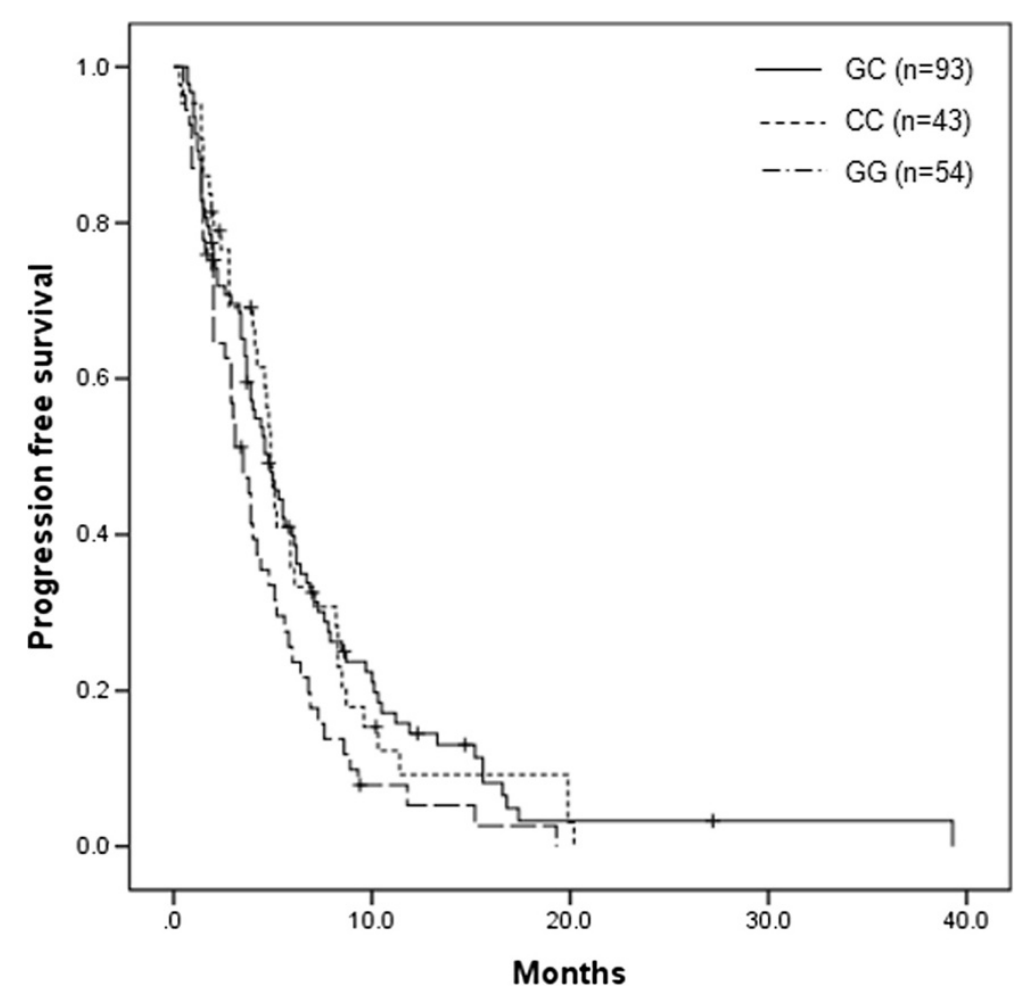

Figure 1 Kaplan-Meier progression-free survival curve according to vascular endothelial growth factor $-634 \mathrm{G} / \mathrm{C}$ polymorphisms $(P=0.043)$.

\section{Discussion}

Identification of patients with potentially poor prognosis after FOLFOX chemotherapy would help us to optimize another treatment protocol for patients with advanced gastric cancer. We reported that immunohistochemical staining for Excision Repair Complementation 1 (ERCC1) may be useful in prediction of the clinical outcome in advanced gastric cancer patients treated with modified FOLFOX4 [17]. We have also shown that the Glutathione S-transferase M1 (GSTM1) positive genotype evidenced a

Table 5 Multivariate analysis

\begin{tabular}{lccc}
\hline & \multicolumn{3}{c}{ Time to progression } \\
\cline { 2 - 4 } Variable & $\mathbf{H R}$ & $\mathbf{9 5 \%} \mathbf{C l}$ & $\boldsymbol{p}$ value* \\
\hline Age & 1.521 & $1.105-2.093$ & 0.010 \\
Gender & 1.313 & $0.939-1.837$ & 0.111 \\
Performance & 2.079 & $0.743-5.816$ & 0.163 \\
Operation & 1.143 & $0.763-1.713$ & 0.516 \\
Stage & 0.941 & $0.763-1.161$ & 0.571 \\
Lauren type & 1.035 & $0.857-1.250$ & 0.720 \\
Number of metastasis & 1.375 & $1.129-1.674$ & 0.002 \\
-634 G/C polymorphism & 1.497 & $1.074-2.088$ & 0.017 \\
\hline
\end{tabular}

*by cox regression test.

VEGF: vascular endothelial growth factor. significantly better time to progression in cases of advanced gastric cancer being treated with FOLFOX [18].

The association of VEGF gene polymorphisms with the risk or prognosis of gastric cancer has already been shown [12,13]. In a Greek study, 634C/C genotype was significantly associated with increased risk of gastric cancer development, and carrying the $-634 \mathrm{C} / \mathrm{C}$ genotype was associated with decreased overall survival [12]. In a Korean study, +936 T/T genotype had a worse overall survival compared to $\mathrm{C} / \mathrm{C}$ genotype, and the $-460 \mathrm{~T} / \mathrm{C}$ or $\mathrm{C} / \mathrm{C}$ genotype was a poor prognostic factor in patients with stage 0 or I gastric cancer [13].

Previous studies have shown that VEGF expression is related to the extent of tumor vascularization and prognosis in solid tumors, and is predictive of resistance to chemotherapy [19]. SNPs in the VEGF gene might influence the delivery of chemotherapy to the cancer cells and may consequently hold predictive information in relation to response [7]. There were several reports of predictive value of VEGF SNPs for bevacizumab treated patients [20-22]. Schultheis et al. [20] reported that recurrent ovarian cancer patients with VEGF $+937 \mathrm{~T}$ polymorphism $\mathrm{C} / \mathrm{T}$ genotype had a longer PFS when treated with cyclophosphamide and bevacizumab. Schneider et al. [21] showed that VEGF -2578AA genotype was associated with a superior median OS, and VEGF -1154A allele also 
demonstrated a superior median OS in patients with advanced breast cancer with paclitaxel plus bevacizumab treatment. Formica et al. [22] reported that VEGF -1154 G/A was an independent prognostic factor for PFS, and VEGF -634 G/C was significantly associated with the response rate in patients with metastatic colorectal cancer patients receiving first-line treatment including fluorouracil, irinotecan, and bevacizumab.

In this study, we assessed six common polymorphisms of the VEGF genes and their association with response and survival in metastatic gastric cancer patients treated with FOLFOX. To our knowledge, this is the first study to demonstrate a relationship between SNPs in the VEGF gene and response to chemotherapy in patients with metastatic gastric cancer. The genotype frequencies of $-634 \mathrm{G} / \mathrm{C},-2578 \mathrm{C} / \mathrm{A}$, or $+936 \mathrm{C} / \mathrm{T}$ in the present study corresponded to those reported in the literature on Korean colorectal cancer patients [23-25], whereas the frequency of the $-1498 \mathrm{C} / \mathrm{T}$ genotype was similar to that of the Japanese prostate cancer patients [26]. Any minor variation could be explained by sample sizes.

There were two reports that showed the predictive value of VEGF SNPs to FOLFOX or XELOX chemotherapy in colorectal cancer $[15,16]$. The inferior response rates and shorter PFS were shown in the patients with VEGF $-2578 \mathrm{C} / \mathrm{A}$ and $405 \mathrm{G} / \mathrm{C}$ genotype who were treated with XELOX [15]. Other study showed that VEGF $-460 \mathrm{~T} / \mathrm{C}$ or $\mathrm{C} / \mathrm{C}$ genotypes were associated with lower response rate to FOLFOX-4 and shorter survival [16]. According to our study, only VEGF -634 G/G genotype showed a significant association with lower response rate and it was translated to short PFS. Shorter overall survival was also shown in Korean colorectal cancer patients with VEGF -634 G/G phenotype [27]. The VEGF -634 G/C likely affects expression at the post-transcriptional level by altering the activity of the internal ribosomal entry site B, thereby enhancing initiation of translation at the AUG start codon and regulating production of the large VEGF isoform, which is translated at an alternative CUG codon [28]. Such changes could be a possible explanation to the low response rates, but several other mechanisms may also be involved. However, we can not specify whether it was the response to 5-FU, oxaliplatin or the combination of both that seemed to be related to SNPs in the VEGF gene or not in this study. None of the rest, of the examined SNPs conferred any clinical significance.

A few studies have reported that VEGF-634 G/C gene polymorphisms are associated with VEGF production. Nonetheless, the results are inconsistent. Awata et al. [29] reported that individuals with the $-634 \mathrm{C} / \mathrm{C}$ genotype had a higher fasting serum VEGF level than those with other genotypes, and that they carried an increased risk of diabetic retinopathy. Meanwhile, Watson et al.
[10] showed that the $-634 \mathrm{G}$ allele is associated with higher VEGF production than the $+405 \mathrm{C}$ allele. In this study, patients with -634 G/G genotypes were associated with higher circulating VEGF levels.

Kim et al. showed that the e VEGF 936 T-allele were associated with inferior survival rates, compared with their corresponding genotypes. However, the VEGF +936 $\mathrm{C} / \mathrm{T}$ genotype showed no relationship with response to chemotherapy or survival in this study. Difference in disease stages, and sample sizes could probably explain some of these discrepancies.

\section{Conclusion}

To the best of our knowledge, this is the first prospective study that has explored the association between VEGF SNPs and clinical outcomes of metastatic gastric cancer patients treated with FOLFOX chemotherapy. The results demonstrated obvious relationships between genetic variations in the VEGF gene and response to FOLFOX chemotherapy, which translated to a significant difference in PFS.

Irinotecan and taxane-based regimens have been used in the treatment of advanced gastric cancer patients, with a similar survival to those attained with FOLFOX $[30,31]$. Irinotecan or taxane-based regimens could be the better alternative for patients with VEGF -634 G/G genotype. These findings deserve confirmation in additional prospective studies.

\section{Competing interests}

Above all authors of this paper do not have potential conflicts of interest include employment, consultancies, stock ownership, honoraria, paid expert testimony, patent applications/registrations, and grants or other funding.

\section{Authors' contributions}

$\mathrm{HJA}$ and HSH carried out the molecular genetic studies, OSY drafted the manuscript. OSY, KHC, KSH, LS, and LJH carried out enrolment and treatment of patients. GCA and CK carried out the immunoassay. OSY, LYS and KHC participated in the design of the study and performed the statistical analysis. LYS, KHC and KHJ conceived of the study, and participated in its design and coordination and helped to draft the manuscript. All authors read and approved the final manuscript.

\section{Acknowledgements}

This paper was supported by the Dong-A University Research Fund.

\section{Author details}

${ }^{1}$ Department of Internal Medicine, Dong-A University College of Medicine, Busan, Korea. ${ }^{2}$ Cancer Genomics Branch, Research Institute, National Cancer Center, Goyang, Gyeonggi-do 410-769, Korea. ${ }^{3}$ Radiation Oncology Branch, National Cancer Institute, Bethesda, Maryland, USA.

Received: 15 August 2012 Accepted: 30 January 2013

Published: 1 February 2013

\section{References}

1. Parkin DM, Bray F, Ferlay J, Pisani P: Global cancer statistics. CA Cancer J Clin 2005, 55(2):74-108.

2. Jung KW, Park S, Kong HJ, et al: Cancer statistics in Korea: incidence, mortality, survival, and prevalence in 2008. Cancer Res Treat 2011, 43(1):1-11. 
3. Wagner AD, Grothe W, Haerting J, Kleber G, Grothey A, Fleig WE: Chemotherapy in advanced gastric cancer: a systematic review and metaanalysis based on aggregate data. J Clin Oncol 2006, 24(18):2903-2909.

4. Pasini F, Fraccon AP, DEM G: The role of chemotherapy in metastatic gastric cancer. Anticancer Res 2011, 31(10):3543-3554.

5. Oh SY, Kwon HC, Seo BG, Kim SH, Kim JS, Kim HJ: A phase II study of oxaliplatin with low dose leucovorin and bolus and continuous infusion 5-fluorouracil (modified FOLFOX-4) as first line therapy for patients with advanced gastric cancer. Acta Oncol 2007, 46(3):336-341.

6. Kim YS, Hong J, Sym SJ, et al: Oxaliplatin, 5-fluorouracil and leucovorin (FOLFOX-4) combination chemotherapy as a salvage treatment in advanced gastric cancer. Cancer Res Treat 2010, 42(1):24-29.

7. Ferrara N, Davis-Smyth T: The biology of vascular endothelial growth factor. Endocr Rev 1997, 18(1):4-25.

8. Tanigawa N, Amaya H, Matsumura M, Shimomatsuya T: Correlation between expression of vascular endothelial growth factor and tumor vascularity, and patient outcome in human gastric carcinoma. J Clin Oncol 1997, 15(2):826-832.

9. Maeda K, Chung YS, Ogawa Y, et al: Prognostic value of vascular endothelial growth factor expression in gastric carcinoma. Cancer 1996, 77(5):858-863.

10. Watson CJ, Webb NJ, Bottomley MJ, Brenchley PE: Identification of polymorphisms within the vascular endothelial growth factor (VEGF) gene: correlation with variation in VEGF protein production. Cytokine 2000, 12(8):1232-1235.

11. Jain $L$, Vargo CA, Danesi $R$, et al: The role of vascular endothelial growth factor SNPs as predictive and prognostic markers for major solid tumors. Mol Cancer Ther 2009, 8(9):2496-2508.

12. Tzanakis N, Gazouli M, Rallis G, et al: Vascular endothelial growth factor polymorphisms in gastric cancer development, prognosis, and survival. J Surg Oncol 2006, 94(7):624-630.

13. Kim JG, Sohn SK, Chae YS, et al: Vascular endothelial growth factor gene polymorphisms associated with prognosis for patients with gastric cancer. Ann Oncol 2007, 18(6):1030-1036.

14. Jain RK: Tumor angiogenesis and accessibility: role of vascular endothelial growth factor. Semin Oncol 2002, 29(6 Suppl 16):3-9.

15. Hansen TF, Garm Spindler KL, Andersen RF, Lindebjerg J, Brandslund I, Jakobsen $A$ : The predictive value of genetic variations in the vascular endothelial growth factor A gene in metastatic colorectal cancer. Pharmacogenomics J 2011, 11(1):53-60.

16. Chen MH, Tzeng CH, Chen PM, et al: VEGF - $460 \mathrm{~T} \mathrm{C}$ polymorphism and its association with VEGF expression and outcome to FOLFOX-4 treatment in patients with colorectal carcinoma. Pharmacogenomics J 2011, 11(3):227-236

17. Kwon HC, Roh MS, Oh SY, et al: Prognostic value of expression of ERCC1, thymidylate synthase, and glutathione S-transferase P1 for 5-fluorouracil/oxaliplatin chemotherapy in advanced gastric cancer. Ann Oncol 2007, 18(3):504-509.

18. Seo BG, Kwon HC, Oh SY: Comprehensive analysis of excision repair complementation group 1, glutathione S-transferase, thymidylate synthase and uridine diphosphate glucuronosyl transferase $1 \mathrm{~A} 1$ polymorphisms predictive for treatment outcome in patients with advanced gastric cancer treated with FOLFOX or FOLFIRI. Oncol Rep 2009, 22(1):127-136.

19. Toi M, Matsumoto T, Bando H: Vascular endothelial growth factor: its prognostic, predictive, and therapeutic implications. Lancet Oncol 2001, 2(11):667-673.

20. Schultheis AM, Lurje G, Rhodes KE, et al: Polymorphisms and clinical outcome in recurrent ovarian cancer treated with cyclophosphamide and bevacizumab. Clin Cancer Res 2008, 14(22):7554-7563.

21. Schneider BP, Wang M, Radovich $M$, et al: Association of vascular endothelial growth factor and vascular endothelial growth factor receptor-2 genetic polymorphisms with outcome in a trial of paclitaxel compared with paclitaxel plus bevacizumab in advanced breast cancer: ECOG 2100. J Clin Oncol 2008, 26(28):4672-4678.

22. Formica V, Palmirotta R, Del Monte G, et al: Predictive value of VEGF gene polymorphisms for metastatic colorectal cancer patients receiving first-line treatment including fluorouracil, irinotecan, and bevacizumab. Int J Colorectal Dis 2011, 26(2):143-151.

23. Chae YS, Kim JG, Sohn SK, et al: Association of vascular endothelial growth factor gene polymorphisms with susceptibility and clinicopathologic characteristics of colorectal cancer. J Korean Med Sci 2008, 23(3):421-427.

24. Park HM, Hong SH, Kim JW, et al: Gender-specific association of the VEGF $-2578 \mathrm{C}>\mathrm{A}$ polymorphism in Korean patients with colon cancer. Anticancer Res 2007, 27(4B):2535-2539.

25. Bae SJ, Kim JW, Kang H, Hwang SG, Oh D, Kim NK: Gender-specific association between polymorphism of vascular endothelial growth factor (VEGF 936 C > T) gene and colon cancer in Korea. Anticancer Res 2008, 28(2B):1271-1276.

26. Fukuda H, Tsuchiya N, Narita S, et al: Clinical implication of vascular endothelial growth factor T-460C polymorphism in the risk and progression of prostate cancer. Oncol Rep 2007, 18(5):1155-1163.

27. Kim JG, Chae YS, Sohn SK, et al: Vascular endothelial growth factor gene polymorphisms associated with prognosis for patients with colorectal cancer. Clin Cancer Res 2008, 14(1):62-66.

28. Huez I, Bornes S, Bresson D, Creancier L, Prats H: New vascular endothelial growth factor isoform generated by internal ribosome entry site-driven CUG translation initiation. Mol Endocrinol 2001, 15(12):2197-2210.

29. Awata $T$, Inoue $K$, Kurihara $S$, et al: A common polymorphism in the 5'untranslated region of the VEGF gene is associated with diabetic retinopathy in type 2 diabetes. Diabetes 2002, 51(5):1635-1639.

30. Kim BG, Oh SY, Kwon HC, et al: A phase II study of irinotecan with biweekly, low dose leucovorin and bolus and continuous infusion 5-fluorouracil (modified FOLFIRI) as first line therapy for patients with recurrent or metastatic gastric cancer. Am J Clin Oncol 2010, 33(3):246-250

31. Overman MJ, Kazmi SM, Jhamb J, et al: Weekly docetaxel, cisplatin, and 5-fluorouracil as initial therapy for patients with advanced gastric and esophageal cancer. Cancer 2010, 116(6):1446-1453.

doi:10.1186/1471-2407-13-43

Cite this article as: Oh et al:: The relationship of Vascular endothelial growth factor gene polymorphisms and clinical outcome in advanced gastric cancer patients treated with FOLFOX: VEGF polymorphism in gastric cancer. BMC Cancer 2013 13:43.

\section{Submit your next manuscript to BioMed Central and take full advantage of:}

- Convenient online submission

- Thorough peer review

- No space constraints or color figure charges

- Immediate publication on acceptance

- Inclusion in PubMed, CAS, Scopus and Google Scholar

- Research which is freely available for redistribution 